\title{
School Social Work and Inclusion \\ of Refugee Students in Greek Schools \\ Teachers' Perspectives and Experiences
}

DOI: 10.47050/66515321.186-210

Irene Katsama, Stefania Bakirtzi

This chapter studies the issue of integrating diversity into primary education and, in particular, focuses on the case of refugee students. It aims to explore the views and perceptions of teachers on issues arising in the school environment that either complicate, obstruct, or enhance the student integration process. The present study explores the crucial contemporary issue of the integration of refugee students into education following recent legislative reforms of intercultural education in Greece and the European Union.

\footnotetext{
Keywords:

diversity

education

inclusion

integration

refugee students

school social work
} 


\section{Diversity and integration in education}

Education contributes significantly to the integration and promotion of social cohesion. As stated in the Convention on the Rights of the Child, every child has the right to attend general education, regardless of race, ethnicity, or mental, physical, psychic or other ability (United Nations, 1989, p. 3). The distinction between students with or without disabilities, natives or foreigners, is formally unaccepted, as schools focus on the common features that students share and the positive effects of any kind of diversity in interaction.

In regard to the term diversity, the question that arises is: Different from whom or from what? Diversity refers to any personal, physical, or demographic feature (such as skin colour, gender, or ethnic origin), while in a deeper context, it refers to attitudes, values and beliefs. More generally, the term has appeared in the literature since the 1970s, when it referred to minorities and women in the workforce (Karanikola \& Pitsou, 2015).

In the modern scientific discourse, the terms difference and diversity usually refer to students who are different from those described by the literature as mainstream (Boethel, 2003).

In a multicultural environment such as a school, an understanding of the distinction between us and the other person, that is, the realisation of identity versus diversity, is necessary for the understanding of relationships. Diversity is a philosophical and anthropological term that identifies the other person (Soulis, 2008; Kandylaki, 2009), highlighting that the other person may be the imaginary other. This can be the opponent, the enemy, or even the cherished, the desirable. As the images of us and one's self are formed at an early age through education, school is an important factor in influencing or altering students' perception of diversity.

In education, a certain class or school population does not necessarily mean a heterogeneous group of students. On the other hand, the term diversity tends to be used for any group of students, however homogeneous it may be, in which most members do not reflect the main characteristics of the broader group (Keil et al., 2007).

Legislation against discrimination on the grounds of racial or ethnic origin, religion, age or sexual orientation has significantly affected educational policies combating discrimination in Europe. According to Article 13 (2000), the European Union has adopted two 
anti-discrimination directives: one on the implementation of equal treatment, irrespective of racial or ethnic origin, which prohibits racial discrimination in the fields of employment, education, social security, health care and access to goods and services, and a second on the formulation of a general framework for equal treatment in employment and occupation on the grounds of religion or belief, age and sexual orientation.

The role of teachers in the management of discrimination becomes essential for the inclusion of students in school and, thus, society on equal terms. With teachers' contribution, the participation of students bearing any kind of diversity in school can enable them to become active members and explore the environment according to their interests and needs. They can also engage themselves in the process of discovery through collaboration with others and develop their personality in an area that cultivates "acceptance, respect, interaction and creativity" (Kontogiannis, 2012, p. 273). The above-mentioned core values are prerequisites for inclusive education.

According to Mel Ainscow and Susie Miles (2009, p. 8), "inclusion or inclusive education" is the "education that refers to all students regardless of their abilities or weaknesses as a result of gender, social order, nationality and of their ability". Inclusion is a complex and dynamic process with multiple educational, political, and social extensions. The term inclusion is often confused with other terms such as integration, from which it can be a conceptual development without, however, identifying with them. The difference is that integration refers to the way certain groups, such as students with disabilities or different linguistic, religious or social minorities, can attend general education, while inclusion focuses on developing the quality of education provided in school so that all students can attend (Soulis, 2008, p. 53).

Inclusive education aims to ensure that all students are welcomed at schools in their neighbourhood in order that they can attend regular classes. Necessary changes need to be made for refugee students to be effectively integrated into the school community since schools have to meet the needs of those students and enable their participation in all aspects of school life (Soulis, 2008). In summary, inclusion refers to "how we develop and design our schools, classes, programmes and activities so that all students learn and participate together" (Inclusion BC, n.d.). 
As Athina Zoniou-Sideri and Evdoxia Deropoulou-Derou argue (2012, p. 17), "inclusion is a way to gain the effective participation of all students throughout the activities of general education". However, continuous and daily efforts are required, with many challenges and constant changes in attitudes and practices that often engender the exclusion of diversity from education. Inclusion is based on empowerment, participation in small groups, the development of collective action, and the enhancement of co-operation among all students. The purpose of the above-mentioned actions is to utilize all students' knowledge, personal experiences, feelings and thoughts, aiming at the cultivation of mutual understanding, the exploration of different ways of managing such issues as co-operation or conflict resolution, the motivation of creativity and the encouragement of the active engagement of all students in the learning process. Equally important are the systematic monitoring and support of all students and their needs at the educational level, their work and their social environment.

Regarding refugee students, the Greek Ministry of Education and Religious Affairs has, as a basic principle, the promotion of measures aimed at educational equality, the elimination of inequalities experienced by students who speak their native language and the assurance of equal opportunities in education for all students in the context promoted by the principles of intercultural education. According to the Government Gazzette (63A/21.09.2016), the objective of the Zones of Educational Priority (ZEPs) is "the equal integration of all students in the education system through the operation of supportive actions" in order to improve learning outcomes.

\section{Refugee Students attending Greek Schools}

Many children, irrespective of the status of their parents, are studying at all levels of education in Greek facilities. In 2016-2017, when 22,000 refugee children were in the country, 800 reception classes were facilitated within public schools, each including 10 to 20 pupils aged between 6 and 15 years. They were offered a 4-hour programme on the Greek language, mathematics, computer science, music, art, theatre and gymnastics (Buchanan \& Kallinikaki, 2018).

According to the Ministry of Education (2017), during the 2017-2018 school year, 1,000 schools across Greece accepted refugee children, 
while 30 kindergartens operated within the refugees' accommodation structure. Specifically, there are "an estimated 2,493 children aged 6-16 who live within the urban fabric (in apartments or hostels) and have already been enrolled in schools throughout Greece at all levels of education. More than 2,360 are estimated to be school-age children (6-16 years old) living within the Inland Refugee Accommodation Structures" (Ministry of Education, 2017). Children aged 6-16 who attended last year's reception classes will join this year's public school morning program. Consequently, 211 teachers have enrolled for 600 reception classes that operate in the morning while 36 permanent teachers of the primary and 33 teachers of the secondary education systems have been appointed to the position of Refugee Training Coordinator1.

About 12,000 refugee children attended Greek schools during the 2018-2019 school year. Aiming to ensure access to school for refugee children staying on the Greek islands, the Regional Education Directors highlighted the positive experiences they have gained in these specific regions (Greek City Times, 2019).

Nevertheless, as the UNHCR (2019) declares, "Refugee children face increased challenges in enrolling at school globally, but their right to education should be safeguarded. The school is a safe space that gives them opportunities for empowerment, while helping integrate into the societies that welcome them". Therefore, the process of enrolling refugee students in Greek schools has encountered many difficulties and obstacles, as several parents' associations throughout Greece have opposed the integration of refugees into the education system, and a number of those associations have protested against refugee students' inclusion and refused to accept them into schools, claiming religious and cultural differences.

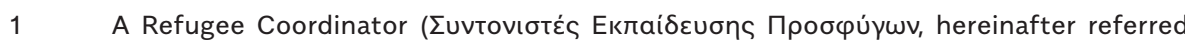
to as an SEP) is a teacher designated to each refugee hosting centre. The number of SEPs depends on the number of refugee residents. The RTCs recommend measures for the proper functioning of the educational units and address issues related to: (1) informing the residents of the host centre of the need for education as a basic means of social inclusion, (2) the implementation of the educational policy of the Ministry of Defence, (3) recording the pupils attending the educational units by age and other criteria, (4) monitoring and coordinating the training provided by all GOs and NGOs, as well as observing quantitative and qualitative elements of the educational actions of other institutions, and (5) the recording of service needs (naftemporiki.gr, 2016). 
In particular, parents seem to claim that the gap between the different cultures is so big that the settlement of immigrants in certain areas would cause problems of adaptation. In some cases, parents' associations highlighted that the quality of education will negatively affect Greek students. Therefore, according to the above view, all refugee students should be excluded from the general education system and their placement in educational groups should be within the "hotspots"2.

The separation of refugee students from the rest of the general population, apart from conflicting with a child's statutory rights, also promotes an exclusionary situation in refugee settlements (United Nations, 1989). In this situation, school social workers manage or work on preventing problems of marginalisation and social exclusion, aiming at the promotion of inclusion in education for all students.

\section{School Social Work and the Inclusion of Diversity in Education}

The need for planning and implementing interventions that aim at the management of diversity at schools appears more than necessary. Internationally, social work has a broad scope of practices in all grades of education. The tradition and culture of each country affect practices of social work. Recently, a connection between social work, social pedagogy and school social work has been implemented in countries such as the United Kingdom, France, Germany and the Netherlands (Lorenz, 2008; Hatton, 2008). Kieron Hatton (2008) underlines the significance of creativity as a strategy for the improvement of services provided at schools and emphasises the cultivation of personal and social skills through their participation in social workgroups. Personal development, self-esteem improvement and social inclusion all contribute to the promotion of children's mental health.

School social work interventions are based on theoretical approaches (critical social work, anti-oppressive) that support and promote the rights of minority students, refugees and immigrant children (Kallinikaki, 2011; Kandylaki, 2010).

2 In Greek, these are called "refugee registration centres", that is, sites where someone is checked if he or she is a refugee, an immigrant or an illegal immigrant. 
Most school social work interventions are based on systems theory, as it takes into consideration the interaction between the individual and the environment. Social work interventions address the needs of all parts of the school community - students, parents and teachers - while also bearing in mind all the interactions and influences the external environment brings into the school community (Katsama \& Bourbaki, 2017).

Systems theory underlines the complexity and diversity of individuals and systems, as they "interact continuously for mutual coexistence" (McMahon, 1996, p. 27). Looking at certain contexts, instead of considering whether the environment has an influence on the individual or the individual has an influence on his or her environment, the question is whether the person is part of his or her environment (Dimopoulou-Lagonika, 2011).

\section{Research Methodology - Purpose and Objectives}

The present research explores how teachers perceive, experience, symbolise, and adopt behaviours towards the inclusion of diversity in education. Its purpose is to explore the views of teachers on issues that arise in the school environment and whether they complicate or enhance and promote the integration process of all students. Emphasis is given to the ways in which teachers contribute to the inclusion of students in their school. Furthermore, the ways in which collaborations between school social workers and teachers can contribute to the effective inclusion of students in education and the community are also explored.

Four research questions were formulated for the exploration of the subject:

1. What are teachers' perceptions concerning inclusion and in what way/how do they work on students' inclusion in the classroom?

2. How do teachers perceive school social workers and how informed are they about their role?

3. In what ways could social workers' and teachers' collaborations contribute to the inclusion of diversity in the school environment?

4. How could inclusive education and co-operation between teachers and social workers contribute to the social integration of groups (refugee students)? 
As already mentioned, in-depth interviews were the main research tool and semi-structured questions were designed accordingly. Pieria, a district of 126,698 people (as of 2011) in the north of Greece, was selected as the target area, as it received a large influx of refugees during 2017. They live in apartments in the centre of the city of Katerini as well as in outlying villages and have attended regular schools in the wider area since September 2017 (Alfavita, 2016; PierikiAlithia, 2017).

Seven primary education teachers participated in the research. Their selection was based on purposive sampling, and their profiles are as follows:

1. A primary school teacher who works in an integration class.

2. A teacher who works in a kindergarten integration class attended by two refugee students.

3. A teacher who works in a primary school in Katerini (with two refugees in their class).

4. The director of a primary school in Pieria that has taken in many refugee students.

5. An SEP (Primary Education) working in the Administrative District of Pieria.

6. An SEP (Secondary Education) working in the Administrative District of Pieria.

7. A teacher who works in a kindergarten integration class attended by four refugee students.

\section{Data Analysis}

The produced data derived from recording and transcribing the interviews (consent for which was given by the respondents). Five individual subject areas resulted from the thematic analysis process and are presented and analysed in turn below, with accompanying quotes from the participants and references to their interview number ${ }^{3}$ :

Inclusive education through integration with the community:

(1) Sense of belonging as the first step for social integration,

(2) Organisation of events at school. numbers were assigned to them in the interviews. The numbers are represented in the text as No. 1, 2, 3, etc., where "No." is the interview number. The gender of the participants is not mentioned since there was only one male teacher involved in the research, and making mention of the participants' gender could reveal the identity of the male teacher. 
$\rightarrow$ Teachers' contribution to inclusion: (1) Preparation of class and teachers' lifelong learning, (2) The use of art as a universal method of communication.

$\rightarrow$ The role of school social work in inclusion: (1) Counseling and support when managing difficult cases, b) Interdisciplinary cooperation when supporting the student.

$\rightarrow$ Obstacles and difficulties: (1) Crowded classes and students' different needs, (2) Linguistic and religious diversity as a constant challenge, (3) Vulnerability of refugee students.

$\rightarrow$ Benefits of integrating diversity into education: (1) Sense of acceptance by the community, (2) Sensitisation to diversity.

\section{Inclusive education through integration with the community}

\section{Sense of belonging as the first step for social integration}

Including diversity at school can contribute to socialisation and community integration. The following quote is a representative one:

When the child attends school he or she feels that he or she is also part of society... I saw that during the school break, the new children were a group by themselves... Now I see that they have started playing with the rest of the children, all together [...] so they slowly become part of the society in which they live, they become a group with the rest of the children, while at the beginning they were a group by themselves due to the language barrier. [Interview No. 1]

In this context, the inclusive education of refugee students in general education classrooms seems to contribute to the elimination of prejudices and stereotypes. It might take time, but all members of the group can learn to co-operate and coexist with diversity.

Attention is now more and more focused on special education and refugees. The important thing is to get the refugee children to know our customs, our school and the Greek students so that both sides can socialise. This, however, can only be achieved with inclusion... [Interview No. 5] 
Bringing all children together, regardless of the difficulties, eventually leads to mutual interaction and connection or even the alteration of stereotypes and prejudices.

\section{Organisation of events at school}

As the participants mentioned, one way that could help groups integrate into the community is to initiate in-school and out-of-school activities and events with the involvement of families. School social workers can assist in organising events aimed at increasing awareness of diversity, bringing together schools, families and communities.

The social worker, with their close contact with the families, will be able to help integrate refugee kids into school so as to organise welcome events [taking place at the school facilities], or an event in regard to ethics and customs or even a cooking event, with both Greek and refugee families preparing meals. I think that this could, in collaboration with social workers, connect the families.

[Interview No. 3]

School is a microcosm of society, and if, for example, an event takes place at school, organised by a social worker, and if this event is able to attract parents, then this is I think the "magic touch" in order to bring people together. [Interview No. 5]

The organisation of events and the involvement of all families in school seem to be factors that contribute to socialisation and therefore the elimination of prejudice.

\section{Teachers' contribution to inclusion \\ Preparation and lifelong learning}

All respondents agree that teachers are crucially important to students' life in the classroom as they spend many hours with them. In particular, they argue that a lot of preparation is required for the inclusion of students. As argued by one respondent, teachers must "prepare" the classroom and, depending on the situation, devote some time to talking to the rest of the children about diversity. 
The main thing is the reception of the new students. This means that the teacher, prior to the children's arrival, must do some preparatory work. He or she must explain that the new students will not be able to speak Greek since they come from a foreign country and that they have been through some unpleasant situations. This will help raise awareness in children since whatever happens in society also becomes part of the school, and therefore of the classroom. [Interview No. 6]

Preparation is needed on behalf of teachers so as to differentiate and personalise their teaching. More efforts and responsibilities are needed from their side so as to have the desired result.

[Interview No. 3]

It appears that it is necessary for teachers to adjust their teaching methods so that all students can follow them and participate in their class. According to the above, inclusive education does not concern only the presence of the refugee students in the school environment but also their interaction in the lesson during the teaching process.

An important prerequisite for groups' integration into school seems to be the lifelong learning education of teachers. According to one respondent, teachers' education is necessary not only for the benefit of the refugee students but also for other social groups that may exist in society and be part of a regular class (e.g. Roma students).

I believe it is necessary for us to be educated in certain fields [not just] in this respect, but also in how to engage with other social groups... [Interview No. 2]

\section{The use of art as a universal method of communication}

According to the respondents' views, the use of arts and group games seem to be appealing to all students. Art in education can contribute to developing students' confidence, developing their own personal skills and creativity, which are more important for the smooth integration of the child into school and classroom (Robinson, 1992).

I invest emotionally on children, at least I try to... I want them to express themselves by organising a theatrical play. I think it is a good start to get a kid to express itself. So, this is where we 
should start from [...] a play, some reward, whatever seems to help children. [Interview No. 2]

The importance of implementing school art therapy for the development of self-esteem is underlined by Nikolaos Tsergas (2014). Programmes designed to address children's needs in poor and deprived areas and which aim at preventing school drop-out rates, developing social skills, creating a sense of belonging, improving their performance and enhancing conditions to ensure school success have adopted art therapy techniques (Sutherland, Waldman \& Collins, 2010).

In this context, music, visual arts and theatrical education are mentioned by the respondents as alternative methods of emotional expression for students.

Classes of art, music and theatre contribute a lot to integration... School is not only about Greek language and mathematics, it is also about motion, a theatrical play or music [...] all these give the joy of inclusion and a sense of belonging to children. [Interview No. 4]

The use of colour and music is also very useful... numbers, one could do something with numbers, as these are common to everybody. [Interview No. 6]

\section{The role of school social work in inclusion}

In this section, teachers underline the role of school social workers in integrating students into their school.

\section{Counseling and support in managing difficult cases}

According to one respondent, school social workers should support teachers and co-operate with them closely.

Social workers could make suggestions to teachers regarding children's integration into the classroom [...] and also support the management of various children's behaviour... [Interview No. 1]

The following respondent, who appears to share the same view, describes counseling as a way to manage challenging situations appearing in class. 
To be by my side so as to advise me, to manage some diverse children's cases, as he or she-as an expert-knows how to handle them... I cannot know everything, it is impossible... [Interview No. 2]

It seems that teachers separate educational issues from those of behaviour, which are more of a task for social workers. In addition, it is noteworthy that the respondent uses the term expert to describe the social worker, which indicates the necessity of having social workers in education and the need for someone to have "authority" and expertise with regard to specific cases.

There must be a social worker, at least one or two, per school. I believe their expertise will primarily help us, the teachers, who do not have the knowledge of approaching children from another point of view. [Interview No. 3]

The respondents also focused on the differentiation of the social worker's role from that of the teacher: the latter is more interested in teaching and learning while the former focuses more on the approach and management of "sensitive issues" (Kandylaki, 2010).

Social workers approach some situations quite differently; we, as teachers, are interested in learning and teaching. You [the social worker] approach more sensitive issues, i.e. I believe you have a supporting role, you approach children in a different way... [Interview No. 6]

\section{Interdisciplinary co-operation when supporting the student}

Two participants precisely described the specific role of the social worker in education:

Co-operation with a social worker will enable us to approach the family and to be able to integrate the child into society in better ways, I believe in the connection of school with society and the social worker. [Interview No. 3]

The social worker plays an important bridging role between the family and the children. Whenever a teacher talks with a social 
worker, all problems arising in class are mentioned, and the social worker gives solutions... [Interview No. 4]

Researchers have claimed that the school social worker is a "bridge" between the school, families and the community. They suggest that the school social worker can open the window of communication with parents and contribute to contacts and communication among teachers, families and children (Kallinikaki, 2015; Kandylaki, 2009; BoydWedd, 1996). Teachers expecting social workers "to give solutions" demonstrates their need to co-operate with other professionals for the better management of certain cases arising in their class.

As the teachers suggested, school social workers, in collaboration with the school's principal and teachers, may be able to identify the issues that need to be addressed.

So, the more people deal with children and who are qualified to do so, the better they can form an interdisciplinary team. It is better than being by myself, as a teacher. [Interview No. 5]

The school social workers, along with teachers, will be able to evaluate each case better during a school day. [Interview No. 4]

\section{Obstacles and difficulties}

In the following section teachers underline the obstacles and difficulties they come across.

\section{Crowded classes and different students' needs}

When you are in sixth grade, for example, you can see that students have reached a particular educational level. When a new student comes who does not understand the language and must attend the sixth grade, you have to deal with this child to teach him or her the basics... Each educational class lasts for 45 minutes, and classes are attended by 25-28 children. How much time does a teacher really have to deal with each child separately, how much time does he or she really have to deal with a refugee who doesn't know the language? [...] How much time can he devote to doing his job in the right way and basically not being unfair to anybody since the goal is equality? [Interview No. 6] 
The teachers' despair is evident, as they need support to handle the multiple different cases and needs of students.

The teacher needs a lot of help and support as there are far too many children in the classroom [...] however, every year, the less the number of children, the better the situation is, and this year I do not have any "difficult" cases, unoriented, or disruptive children in the classroom. Last year I had four and I was living in chaos, "fighting with the beasts". They were all supposed to be mainstream kids [...] if the social worker cannot intervene in such cases, who can really help me? Do I have to do everything by myself? [Interview No. 2]

At this point, it is worth mentioning the use of the phrases "difficult cases" and "I was living in chaos, fighting with the beasts". Both phrases show the teacher's tension and how difficult it is to handle such situations, while at the same time highlighting the necessity of having social workers at school to handle such cases, seeing as the teachers themselves feel "helpless".

These participants' views are confirmed by Villa et al. (1996), whose research data suggests that teachers who teach small groups of 15 to 21 students express more positive views about inclusive education compared to those who teach in more crowded classrooms, that is, from 22 to 30 students.

\section{Linguistic and religious diversity as a constant challenge}

The fear of diversity also appears in the words of the participants when they express their stress and anxiety about the reaction of native students' parents (reactions that were described earlier in this chapter) to the integration of refugee children into the classroom.

You do not really know how parents of children who attend regular education will react when they see a refugee child in the classroom. Everyone has his or her prejudices and racism is part of our lives [...] and that is exactly the part one needs to manage best, how the rest of the parents will accept the child. [Interview No. 5] 
The above-mentioned view is confirmed by Dominelli (1998), who highlights that racism causes problems both in minority groups that are culturally and racially diverse as well as in majority groups.

Another respondent highlighted the difficulty with the rest of the class accepting the new students in the classroom:

Children consider the class as their own and they perceive new students as intruders, as something foreign entering their class, and certainly the foreign element, when coming from another country or ethnicity, another culture or another language, makes the situation more difficult. [Interview No. 6]

The use of the words "intruders" and "foreign" and the phrase "the foreign element [...] makes the situation more difficult" are typical and are expressions that hide deeply structured prejudices and stereotypes towards diversity, coexisting with fear. Some of the respondents also seem to use the word "different" while others use the term "new students" in order to define or refer to the refugee children, reproducing, in a subconscious way, discrimination patterns.

Particularly interesting is the fact that differences such as culture, language and religion are seen as factors of difficulty in teachers' views. Language is an important factor contributing to difficulties, since communication is the main principle of social interaction. Given this, it is almost impossible to capture a social interaction that does not involve communication (Hogg \& Vaughan, 2010). Based on the above, a different language can be an obstacle to communication, since misunderstandings can occur between a teacher and a student:

These kids represent a new element, that is why we do not understand their language. It is possible that one of them says something and I will not understand. I might be doing something wrong for a child... [Interview No. 1]

What seems to worry the respondents is the possibility of causing further harm to students. The lack of an interpreter leaves teachers "exposed", leading to misunderstandings that might further isolate students from their teachers. Different languages, other than being 
a barrier to communication, could also be a cause of prejudice and stereotypical behaviours towards different groups.

There are a lot of difficulties, let us not try to sugar-coat the situation. For teachers, a different language constitutes a major obstacle. For younger children, it is much easier to communicate with their peers in non-verbal ways. As for the older children, this is not the case [...] and one can also see how isolated those kids are in the classroom... [Interview No. 3]

This view seems to be supported by Whorf (1956), who referred to the term "linguistic relativity". According to this theory, language determines thought, and people who speak different languages might see the world in a different way and basically live in different cognitive worlds (Hogg \& Vaughan, 2010, p. 704). Nevertheless, the respondents mainly refer to the realistic and practical obstacles a different language sets, rather than the conceptual ones. It seems that a different language is a major obstacle for almost all the respondents, who have tried to find ways to initiate communication with children. The significance of non-verbal communication is stated in the following quote. As well as the different languages, the students' different religion is also considered as an obstacle by teachers.

Another problem is [...] of course the issue of religion. It is a very important one. Students are not obliged to pray, to follow our rituals, but at the time of prayer in the morning they all stand in line. They may not follow it, but they try to understand. [Interview No. 4]

Challenges [...] are [...] religious ones [...] I see that children, not all of them, have some issues regarding this part... for example, the fact that they do not want to attend and be present at the time of prayer. They could just stand nearby, because all school announcements are made after prayers. We have got the tradition of starting every morning with prayers, and then the announcements from the principal follow... [Interview No. 3]

Students may not be obliged to participate in prayers; however, they should stand in line and "try to understand". In the same context, 
the respondent argues that children's attendance during prayers is a necessity, since all announcements are made after the prayers, and this is why their presence is considered important. In both cases, the language used during the prayers and when the principal makes the announcements is Greek. Language was mentioned as a difficulty, but despite the fact that these students do not understand Greek, it seems that no action has been taken for them to listen to announcements in their own language.

\section{The vulnerability of refugee students}

Teachers express the view that, in some cases, certain behaviours of students at school are difficult to manage. They mention aggressive attitudes and isolation, attributing both behaviours to the children's past traumatic experiences "in times of war".

\section{A difficulty for refugee children is what they carry with them. \\ That is, the dark look in their eyes. It is not because their soul is dark, it is because they have been through many experiences. Seeing a child, one can often think that he or she is aggressive. One cannot judge why he or she is aggressive, or why he or she has a dark look in his or her eyes, or what this child carries with him or her. These obstacles, which then lead to behavioural difficulties, aggression, etc., appear in both young and older children. [Interview No. 3]}

These children have lived in times of war, in difficult situations. They often have anger and an aggressive attitude towards other students. [Interview No. 4]

It seems that the respondents are sensitive to the emotional state of the children and are aware of the traumatic experiences they suffered in their countries. They are trying to understand their behaviour and put it into its proper context. Aggressiveness is a universal way to communicate anger and despair, and maybe it is a way for the children to get through all the changes and challenges of their new life. Research has shown that exposure to war-related traumatic events contributes to mental health disorders and, in some cases, to longterm psychopathology in children and adolescents (Lustig et al., 2004; Betancourt \& Williams, 2008). Nevertheless, it seems that problems 
concerning interpersonal relationships are attributed only to the refugee students, and they should also be examined in the context of their relationship with other students and teachers.

The difficulty teachers face with handling the aggressive cases of refugees is evident. It also seems that teachers have difficulty with managing "sensitive issues" that arise in the school environment.

\section{Benefits of integrating diversity into education}

The results of the data analysis mentioned two factors as benefits of the integration of diversity: (1) a feeling of acceptance by the community, and (2) sensitisation to diversity.

\section{Sense of acceptance}

According to teachers, the benefits of involving all students in education are linked to the quality of their school life.

First of all, children who are part of inclusive education are accepted and recognised. For me, all children certainly have the right to be accepted by the school community. [Interview No. 1]

The participation of all students (in spite of their diversity) in school positively contributes to strengthening their self-esteem as learners. This can only happen through their acceptance and recognition in the school environment (Katsama \& Bourbaki, 2017).

It is not only the new child who gains but also the other ones, it is a two-way link that affects both sides individually as well as the group of students in a holistic way, and this is what we try to do, including me. If children in the class are helped by the mainstream children, they will feel accepted. [Interview No. 5]

Through such a process of inclusion, it seems that children learn to co-operate with each other and help one another, resulting in them feeling accepted by their peers.

\section{Sensitisation to diversity}

Interaction can work positively to raise awareness of the community as a whole. The students' interaction in the school area gives them 
an opportunity to manage stereotypes and prejudices and, with the teacher's contribution, to become more aware of diversity.

We learn to collaborate and not to look at others strangely just because they are different, since this is the secret to softening all differences, all hatred, all tension... [Interview No. 2]

In my opinion, the first and most important benefit for people is to change their values, to figure out what is around us and how to deal with situations. I think the benefit that Greek students gain from the inclusion of refugees in education is much greater than the one refugees gain. I think the main thing is for children to be able to see what is happening in the world. [Interview No. 3]

Stereotypes and prejudices are cultivated in children from an early age. In this respect, it is necessary to handle stereotypes and prejudices in the field of education to prevent future separating behaviours (Nesdale, 2001). As the respondents wisely mentioned, the modification or even change of values seems necessary, although this is quite a demanding and difficult procedure.

\section{Conclusion}

The present chapter focused on the strengths of and obstacles to the integration procedure of refugee children in general education, based on teachers' views and perspectives.

Teachers reported the importance of sensitising the rest of the classroom (sensitisation to diversity) as well as highlighting the necessity of their own preparation for welcoming new students through the modification of their teaching strategy and lifelong learning.

Regarding the role of the school social worker in integrating diversity into education and the school community, the respondents expressed the need for close co-operation with social workers in regard to managing difficult situations in the classroom. According to them, the role of school social workers could positively contribute to connecting families with the school and the community. The collaboration between school social workers and teachers could contribute to the latter having the best possible contact with the children and their families. The respondents concluded that the expertise of school social workers 
can also contribute to children's effective inclusion in the classroom and in the school.

Crowded classes, combined with differing educational needs, emerged as obstacles. In this context, the limited time available for teachers, combined with a plethora of different individual needs, makes the management of the situation difficult. It appears that teachers are required to handle issues that are far removed from the school curriculum, and according to the produced data, it is preferable for these to be handled in co-operation with social workers who have the necessary expertise and professional experience. Teachers referred to such issues as managing parents' stereotypes and prejudices towards new students, incidents of domestic violence, and the violent behaviour of refugee students due to past war experiences.

According to the respondents, the language barrier prohibits communication with the students, while the different religion makes students' participation in the time of prayer difficult, both resulting in the exclusion of children from their morning briefing on school events.

With regard to integrating diversity into education, there are multiple benefits. On the one hand, there is the "sense of acceptance" and belonging that the new students feel as a result of inclusive education, and on the other hand, there is the fact that the rest of the students learn to live and collaborate by overcoming stereotypes and prejudices. Thus, all groups are prepared for positive interactions in adult life.

The school needs to be able to integrate students coming from vulnerable groups of the population. In these cases, however, the school needs support from social workers, as both individual and community integration is required.

Inclusive education programmes should be designed with a clear vision, inspired by values and principles such as acceptance and respect, based on human rights, ensuring equal opportunities in education for all students in the sense of equal, dignified and non-discriminatory access to the right of education.

It seems that teachers are challenged to reconsider their values not just personally but socially as well. During the current research, they expressed their feelings with honesty, demonstrating at the same time their deep interest in and genuine care for all students. They also did not hesitate to admit their need for support, realising the responsibility of the school as a key institution of inclusion. 
Due to the new circumstances at their schools, they adopt an attitude of flexibility in how they perceive the new and the different (religions, rituals, languages, dress codes, attitudes, etc.) and try to cultivate a sense of acceptance, respect, and openness within the students.

It is crucial that the core values of human rights and social inclusion are embodied by school communities, teachers and school professionals. The above-mentioned elements, which are derived from the current data analysis, constitute strong values that need to be integrated into daily practice at schools. A great challenge for teachers and school professionals is to develop and adopt changes in order to be able to manage diversity with acceptance, respect, interaction and creativity. As noted by one respondent, "whatever happens in society also becomes part of the school, and therefore of the classroom", and this quote aptly summarises the significance of the interaction between schools and the contemporary social reality.

\section{References}

$\rightarrow$ Ainscow, M. and Miles, S. (2009). Developing inclusive education systems: How can we move policies forward?, www.ibe.unesco.org/fileadmin/ userupload/COPs/Newsdocuments/2009/0907Beirut/ DevelopingInclusive/ EducationSystems.pdf

$\rightarrow$ Alfavita (2016). ELME Pieria: Refugee Accommodation Center

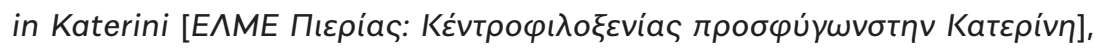
www.alfavita.gr/ekpaideysi/176824_elme-pierias-kentro-filoxenias-prosfygonstin-katerini

$\rightarrow$ Betancourt T. S. and Williams T. (2008). Building an evidence base on mental health interventions for children affected by armed conflict, International Journal of Mental Health, Psychosocial Work and Counseling in Areas of Armed Conflict, 6(1), 39-56.

$\rightarrow$ Boethel, M. (2003). Diversity. School, Family \& Community Connections. Austin,: Southwest Educational Development Laboratory.

$\rightarrow$ Boyd-Webb, N. (1996). Social Work Practice with Children. New York: The Guildford Press.

$\rightarrow$ Buchanan, A. and Kallinikaki, T. (2018). Meeting the needs of unaccompanied children in Greece, International Journal of Social Work, 61(5), 1-49.

$\rightarrow$ Dimopoulou-Lagonika, M. (2011). Social Work methods: From Individual

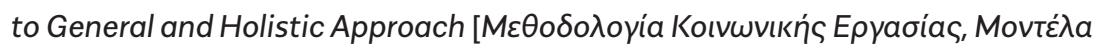




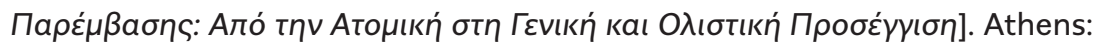
Topos Publications.

$\rightarrow$ Dominelli, L. (1998). Anti-racist Social Work. Palgrave: Macmillan.

$\rightarrow$ European Union. (2000). Council Directive 2000/43/EC of 29 June 2000 implementing the principle of equal treatment between persons irrespective of racial or ethnic origin, https://eur-lex.europa.eu/LexUriServ/LexUriServ. do?uri=CELEX:32000L0043:en:HTML

$\rightarrow$ Greek City Times. (2019). More than 12,000 refugee children attended Greek public schools, https://greekcitytimes.com/2019/05/31/more-than-12000refugee-children-attended-greek-public-schools/

$\rightarrow$ Hatton, K. (2008). New Directions in Social Work Practice. Exeter: Learning Matters.

$\rightarrow$ Hogg, M.A. and Vaughan, G.M. (2010). Social Psychology. Athens: Gutenberg.

$\rightarrow$ Inclusion BC (n.d.). What is Inclusive Education?, https://inclusionbc.org/ourresources/what-is-inclusive-education/

$\rightarrow$ Kallinikaki, Th. (2011). Introduction to Theory and Practice of Social Work

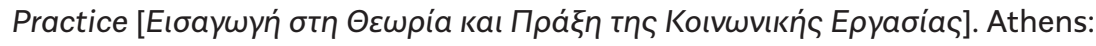
Topos Publications.

$\rightarrow$ Kallinikaki, Th. (2015). Evaluation of social work practice in educational

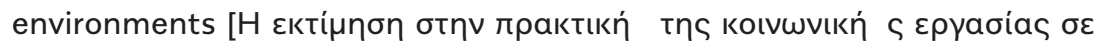

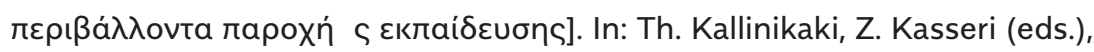

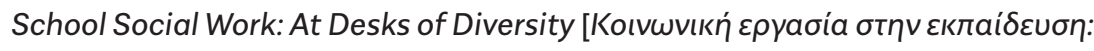

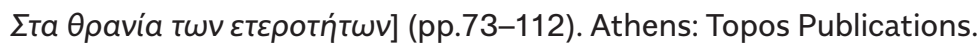

$\rightarrow$ Kandylaki, A. (2009). Social Work in a multicultural environment [Koıvwvikń

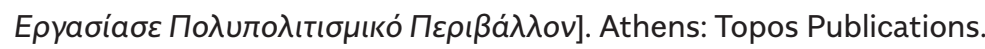

$\rightarrow$ Kandylaki, A. (2010). Qualitative research concerning sensitive issues in social

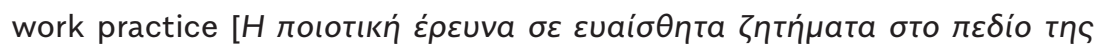

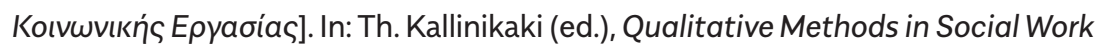

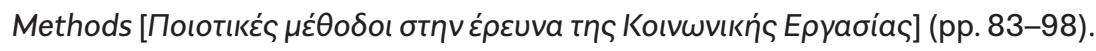
Athens: Topos Publications.

$\rightarrow$ Karanikola and Z., Pitsiou, X. (2015). Outline of the actions of the Ministry of Education with regard to protection of cultural diversity in Primary and Secondary Education. A qualitative study of the thematic analysis of the annual reports of the Ministry of Education to the National Commission for Human

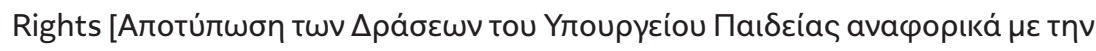

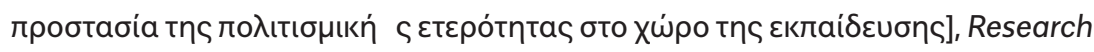
in Education Laboratory of Pedagogical Research and Educational Practices Department of Preschool Education Sciences, 4, 128-151. 
$\rightarrow$ Katsama, I. and Bourmpaki, E. (2017). Bullying in primary education. A social work intervention with students, Journal of Education and Social Policy, 4(3), 98-111.

$\rightarrow$ Keil, M., Amershi, B., Holmes, S., Jablonski, H., Lüthi, E., Matoba, K., Plett, A. and Unruh K. (2007). International Society for Diversity Management, www. idm-diversity.org

$\rightarrow$ Kontogiannis, A. (2012). Art and creative expression in special education

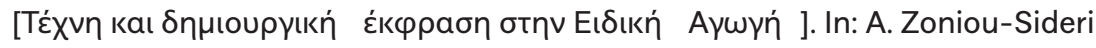

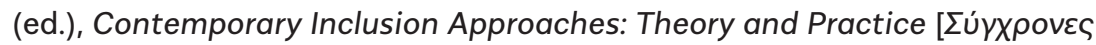

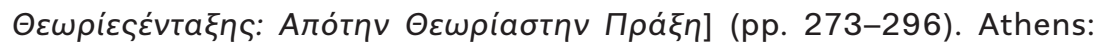
Pedio Publications.

$\rightarrow$ Lorenz, W. (2008). Towards a European Model of Social Work, Australian Social Work, 61(1), 7-24.

$\rightarrow$ Lustig S. L., Kia-Keating M., Knight W.G., Geltman P., Ellis H. and Kinzie J.D. (2004). Review of child and adolescent refugee mental health, Journal of the American Academy of Child \& Adolescent Psychiatry, 43(1), 24-36.

$\rightarrow$ McMahon, M.O.N. (1996). The General Method of Social Work Practice: A Generalist Perspective. Boston-London: Allyn \& Bacon.

$\rightarrow$ Ministry of Education (2017). "2017-2018: All refugee children in school"Interview of the Deputy Secretary General of the Ministry of Education,

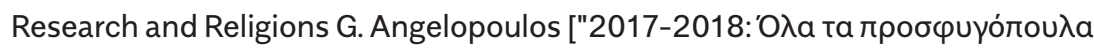

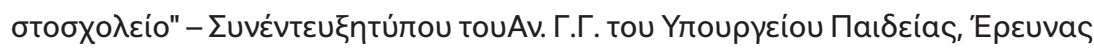

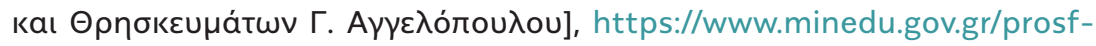
ekpaideusi-m/30920-18-10-17-2017-2018-ola-ta-prosfygopoula-sto-sxoleio

$\rightarrow$ Naftemporiki.gr (2016). The decision to establish reception structures for the education of refugees. [ $\Sigma$ то ФЕК $\eta$ aró

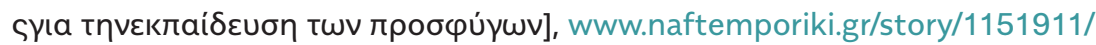
sto-fek-i-apofasi-gia-tin-idrusi-domon-upodoxis-gia-tin-ekpaideusi-tonprosfugon

$\rightarrow$ Nesdale, D.(2001). Social identity and the development of children's group attitudes, Child Development, 72(2), 506-517.

$\rightarrow$ PierikiAlithia (2017). The "village" of immigrant-refugees was inaugurated

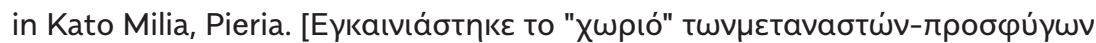

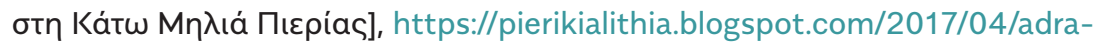
refuges-katomilia.html

$\rightarrow$ Robinson, M. (1992). Mastery learning in public schools: Some areas of restructuring, Education, 113(1), 121-126. 
$\rightarrow$ Soulis, S. G. (2008). A school for all. From Research to Practice: The pedagogy

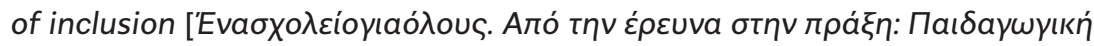

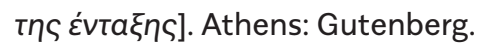

$\rightarrow$ Sutherland, J., Waldman, G., Collins, C. (2010). Art Therapy Connection: Encouraging Troubled Youth to stay in School and Succeed, Journal of the American Art Therapy Association, 27(2), 69-74.

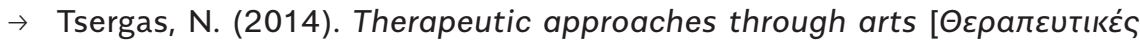

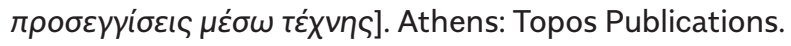

$\rightarrow$ UNHCR (2019). The Global Report, www.unhcr.org/the-global-report.html

$\rightarrow$ United Nations (1989). Convention on the Rights of the Child. Treaty Series, Vol. 1577, www.refworld.org/docid/3ae6b38f0.html

$\rightarrow$ Villa, R., Thousand, J., Meyers, H., Nevin, A. (1996). Teacher and administrator perceptions of heterogeneous education, Exceptional Children, 63, 29-45.

$\rightarrow$ Whorf, B. L. (1956). Language, thought and reality. Cambridge, MA: MIT Press.

$\rightarrow$ Zoniou-Sideri, A., Deropoulou-Derou, E., Vlachou, A. (2012). Disability and Education Policy. Critical Approach in Special and Inclusive Education [Avarnpia

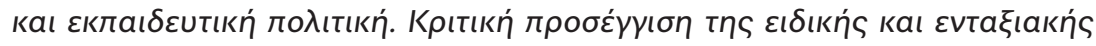
$\varepsilon \kappa \pi a i ́ \delta \varepsilon \cup \sigma \eta \varsigma]$. Athens: Pedio Publications. 